\title{
Disease-specific plasma levels of mitokines FGF21, GDF15, and Humanin in type II diabetes and Alzheimer's disease in comparison with healthy aging
}

\author{
Maria Conte $(\mathbb{D}$ - Jacopo Sabbatinelli • Antonio Chiariello • Morena Martucci • Aurelia \\ Santoro • Daniela Monti • Marina Arcaro • Daniela Galimberti • Elio Scarpini • \\ Anna Rita Bonfigli • Angelica Giuliani • Fabiola Olivieri • Claudio Franceschi • Stefano Salvioli
}

Received: 31 July 2020 / Accepted: 13 October 2020 / Published online: 31 October 2020

(C) The Author(s) 2020

\begin{abstract}
Fibroblast Growth Factor 21 (FGF21), Growth Differentiation Factor 15 (GDF15), and Humanin (HN) are mitochondrial stress-related mitokines, whose role in health and disease is still debated. In this study, we confirmed that their plasma levels are positively correlated with age in healthy subjects. However, when looking at patients with type 2 diabetes (T2D) or Alzheimer's disease (AD), two age-related diseases sharing a mitochondrial impairment, we found that GDF15 is elevated in T2D but not in AD and represents a risk factor for $\mathrm{T} 2 \mathrm{D}$ complications, while FGF21 and HN are lower in AD but not in T2D.
\end{abstract}

Supplementary Information The online version of this article (https://doi.org/10.1007/s11357-020-00287-w) contains supplementary material, which is available to authorized users.

M. Conte - A. Chiariello · M. Martucci - A. Santoro •

S. Salvioli

Department of Experimental, Diagnostic and Specialty Medicine (DIMES), University of Bologna, Bologna, Italy

\section{Conte $(\bowtie) \cdot$ S. Salvioli}

Interdepartmental Center "Alma Mater Research Institute on Global Challenges and Climate Change (Alma Climate)",

University of Bologna, Bologna, Italy

e-mail:m.conte@unibo.it

J. Sabbatinelli · A. Giuliani · F. Olivieri

Department of Clinical and Molecular Sciences (DISCLIMO),

Università Politecnica delle Marche, Ancona, Italy

D. Monti

Department of Experimental and Clinical Biomedical Sciences

"Mario Serio", University of Florence, Florence, Italy
Moreover, FGF21 reaches the highest levels in centenarian' offspring, a model of successful aging. As a whole, these data indicate that (i) the adaptive mitokine response observed in healthy aging is lost in age-related diseases, (ii) a common expression pattern of mitokines does not emerge in $\mathrm{T} 2 \mathrm{D}$ and $\mathrm{AD}$, suggesting an unpredicted complexity and disease-specificity, and (iii) FGF21 emerges as a candidate marker of healthy aging.

Keywords GDF15 · FGF21 · Humanin · Aging · $\mathrm{AD} \cdot \mathrm{T} 2 \mathrm{D}$
M. Arcaro - D. Galimberti · E. Scarpini

Fondazione Ca' Granda IRCCS Ospedale Maggiore Policlinico, Milan, Italy

D. Galimberti · E. Scarpini

Dino Ferrari Center, University of Milan, Milan, Italy

A. R. Bonfigli

Scientific Direction, IRCCS INRCA, Ancona, Italy

F. Olivieri

Center of Clinical Pathology and Innovative Therapy, IRCCS

INRCA, Ancona, Italy

C. Franceschi

Laboratory of Systems Medicine of Healthy Aging and

Department of Applied Mathematics, Lobachevsky University,

Nizhny Novgorod, Russia 


\section{Introduction}

Aging is a complex and progressive phenomenon characterized by a decline and a reshape in normal biological functions, leading to the appearance of the aging phenotype, which is usually accompanied by the presence of chronic degenerative diseases, even though a minority of cases can escape this destiny and reach extreme age in good health. We have conceptualized that healthy aging, geriatric syndromes (such as frailty), and age-related diseases (ARDs) are part of a continuum where precise boundaries do not exist but the rate of aging can be different, leading to longevity (low rate) or ARDs (high rate) [1]. In the last decades, several theories have been proposed about the molecular and cellular mechanisms at the basis of the aging process and it is generally acknowledged that the mitochondria play a key role. Mitochondria are fundamental to produce cellular energy currency and are involved in a variety of metabolic pathways. The aging process is characterized by a progressive mitochondrial dysfunction accompanied by increased production of Reactive Oxygen Species (ROS), considered as one of the key hallmarks of a variety of several age-related pathologies, such as neurodegenerative diseases, metabolic diseases, cardiovascular diseases, and cancer [2,3]. Mitochondrial dysfunction represents a stress condition that elicits an adaptive response which is not confined into the cell but can also spread to distal tissues by means of soluble mediators indicated as mitokines [4]. Mitokines include a variety of circulating proteins and peptides released by different cell types that act as hormones [5, 6]. Fibroblast Growth Factor 21 (FGF21), Growth Differentiation Factor 15 (GDF15), and Humanin $(\mathrm{HN})$ are among the most studied mitokines. Consistently with the idea that mitochondrial dysfunction increases with age, the plasma levels of these mitokines are strongly associated with aging and many ARDs [5-7].

Alzheimer's diseases (AD) and type 2 diabetes (T2D) are among the most common and important ARDs, and both share a metabolic and inflammatory background [7, 8]. Accordingly, AD has been also proposed as Type 3 diabetes [9]. Most importantly, AD and T2D also share a mitochondrial dysfunction [10,11], suggesting a possible similarity in the expression of mitokines in the two conditions. FGF21 is a stress hormone belonging to the FGF family. There is evidence that FGF21 counteracts age-related metabolic changes and promotes the maintenance of health and longevity. Studies on animal models demonstrate that the overexpression of FGF21 is associated to the extension of lifespan, and thus, FGF21 is considered as a pro-longevity hormone $[12,13]$ with anti-inflammatory activity $[14,15]$. It was also demonstrated that FGF21 is implicated in the regulation of energy metabolism and homeostasis [16], and circulating FGF21 levels have been reported to be increased in metabolic stress conditions, such as obesity, insulin resistance, and T2D, $[13,17]$ and interpreted as a sort of homeostatic response to counteract the metabolic stress. Accordingly, FGF21 is in fact considered as a possible therapeutic approach for metabolic disorders such as T2D $[18,19]$. Other studies also suggest a neuroprotective role against pathologies such as $\mathrm{AD}[20,21]$.

GDF15 is a stress response molecule belonging to the transforming growth factor- $\beta$ (TGF- $\beta$ ) superfamily. GDF15 is produced in response to mitochondrial and inflammatory stressors and is involved in many ARDs, such as cancer, T2D, obesity, and cardiovascular and neurodegenerative diseases. Recent studies demonstrate that GDF15 strongly correlates with aging and is considered a marker of biological age [5, 22-24]. Moreover, GDF15 seems to have protective roles against local and systemic inflammation $[25,26]$. It is now well known that high GDF15 levels are associated with insulin resistance and T2D, and GDF15 has been therefore considered a diagnostic biomarker of T2D [27, 28]. However, little is known about its possible involvement in AD.

$\mathrm{HN}$ is a 24-amino acid mitochondrial DNA-encoded peptide involved in many biological processes associated with inflammatory response, oxidative stress, and apoptosis $[29,30]$. HN was discovered for its neuroprotective role against $\mathrm{AD}$ [31]; however, $\mathrm{HN}$ acts as cytoprotective molecule also in T2D, cardiovascular disease, atherosclerosis, and cancer [6]. The role of $\mathrm{HN}$ in aging is still debated. Some studies showed a decrease of $\mathrm{HN}$ with aging $[32,33]$, while others showed an agerelated increase of $\mathrm{HN}$ at plasma level [5, 34].

Within the framework of the continuum hypothesis mentioned earlier, we aimed to test the hypothesis that it is possible to identify a sort of trend for mitokine expression from healthy aging to ARDs, as well as similarities and differences between ARDs sharing a common ground of mitochondrial dysfunction such as T2D and $\mathrm{AD}$. To this purpose, we have studied the plasma levels of these three mitokines in a group of $>500$ agematched elderly characterized by different types of aging: healthy controls, centenarians' offspring (OFF), and 
patients affected by T2D or AD. Of note, OFF are characterized by a better health status with respect to their age-matched peers and are considered as a reliable example of healthy aging $[35,36]$. We found that mitokine patterns are different not only between healthy people (OFF and controls) and patients but also within patient groups, suggesting that mitokine expression regulation is more complex than expected.

\section{Material and methods}

Subjects

A total of 569 subjects in the age range 52-88 years were recruited and divided into five groups, according to their healthy or pathological status: 102 centenarian offspring (OFF), 92 healthy controls (HC), 162 type 2 diabetes (T2D) patients without complications (T2DnC) and 93 T2D patients with complications (T2DC), and 120 patients with Alzheimer's disease (AD) (Table 1). All subjects were enrolled in Italy in the framework of previous projects as described in Bucci et al. [36] for OFF, Testa et al. [37] for T2D patients and HC, and Sims et al. [38] for AD patients. The study protocols were approved by the following Ethical Committees (EC): EC of Sant'Orsola-Malpighi University Hospital, Bologna, Italy (Ethical clearance EM 157/2011/U issued on Nov. 25, 2011) for OFF, Institutional Review Board of Italian National Research Center on Aging (INRCA) for HC and T2D (Ethical clearance 34/CdB/ 03), and Comitato Etico Milano Area 2 for AD. All subjects signed informed consent before blood withdrawal and interviews to collect data on health status, clinical anamnesis, and details on medications. Subjects affected by malignant neoplasia and/or those in therapy with immune suppressor drugs (like cyclosporine, methotrexate, glucocorticoids) or anticoagulant drugs were excluded from the study. As far health status, OFF and $\mathrm{HC}$ were free of clinically evident major diseases. For T2D patients, the inclusion criteria, the clinical information collected from each subject, and the presence of diabetic complications were as reported in Testa et al. and Mensà et al. [37, 39]. All AD patients were sporadic cases, and no one had T2D-related comorbidities. No difference in terms of mitokine levels was observed between early onset and late onset patients, so they were considered together.

\section{Data collection}

For all subjects, blood was drawn in the morning after overnight fasting. All samples were processed to collect plasma. Plasma was obtained within $4 \mathrm{~h}$ from venipuncture by centrifugation at $2000 \mathrm{~g}$ for $20 \mathrm{~min}$ at $4{ }^{\circ} \mathrm{C}$, rapidly frozen and stored at $-80{ }^{\circ} \mathrm{C}$.

Serum concentrations of $\mathrm{HbA} 1 \mathrm{c}$, uric acid, azotemia, triglycerides, ApoA1, ApoB, and highly sensitive Creactive protein were measured by standard biochemical assays in $\mathrm{HC}$ and T2D patients. Estimated glomerular filtration rate (eGFR) was calculated according to CKDEPI (Chronic Kidney Disease Epidemiology Collaboration) equation based on serum creatinine, age, sex, and ethnicity [40].

APOE genotyping was performed by 7500 Fast Real Time PCR System (Applied Biosystems): DNA samples were genotyped for two APOE single-nucleotide polymorphisms (SNPs; rs429358 and rs7412) and relative results defined $\mathrm{APOE} \varepsilon 2, \varepsilon 3$, and $\varepsilon 4$ alleles. We assigned APOE $\varepsilon 4$ status as APOE $\varepsilon 4$ negative $(\varepsilon 4-)$ for APOE $\varepsilon 2 / \varepsilon 3$ and APOE $\varepsilon 3 / \varepsilon 3$ (non-carriers) and APOE $\varepsilon 4$ positive $(\varepsilon 4+)$ for APOE $\varepsilon 2 / \varepsilon 4$, APOE $\varepsilon 3 / \varepsilon 4$, or APOE $\varepsilon 4 / \varepsilon 4$ (carriers of at least one copy of the APOE $\varepsilon 4$ allele).

GDF15, FGF21, and HN concentrations were determined in plasma samples by ELISA assay using commercial kits, highly specific for the detection of each human mitokine: R\&D for GDF15 (DGD150: intra- and interassay coefficient of variation (CV) range: $10.9-1.1 \%$ and 4.1-3.0\%, respectively; minimum detectable dose $2.0 \mathrm{pg} /$ $\mathrm{mL}$ ) and FGF21 (DF2100: intra- and inter-assay CV range: $10.2-3.0 \%$ and $10.6-3.1 \%$, respectively; minimum detectable dose $4.67 \mathrm{pg} / \mathrm{mL}$ ) and CUSABIO for $\mathrm{HN}$ (CSB-EL015084HU: intra- and inter-assay CV range: 5.5-0.7\% and $11.8-3.4 \%$, respectively; minimum detectable dose $7 \mathrm{pg} / \mathrm{mL}$ ), according to the manufacturer's instructions. In all the samples, GDF15, FGF21, and HN were measured in duplicate, and the mean values were used in the statistical analyses. The standard curves were determined by simultaneously analyzing a dilution series of standard samples. The final data were obtained in a blind set up by the operator. Synergy ${ }^{\mathrm{TM}}$ fluorometer (BioTek Instruments, Winooski, Vermont, USA) was used to read the absorbance of each plates.

Statistical analysis

The data were analyzed with non-parametric tests since they did not follow a normal distribution. In particular, 
Table 1 Study samples

\begin{tabular}{clllll}
\hline & OFF & HC & T2DnC & T2DC & AD \\
\hline No. of subjects & 102 & 92 & 162 & 93 & 120 \\
Age range (mean \pm SD) & $54-88$ years & $60-87$ years & $60-81$ years & $60-87$ years & $52-87$ years \\
Sex $(N)$ & $(71.10 \pm 7.67)$ & $(68.76 \pm 6.18)$ & $(68.46 \pm 5.30)$ & $(69.34 \pm 5.29)$ & $(72.02 \pm 7.97)$ \\
\hline
\end{tabular}

OFF centenarians' offspring, $H C$ healthy controls, $T 2 D n C$ T2D patients without complications, $T 2 D C$ T2D patients with complications, $A D$ Alzheimer's disease patients

the comparisons among OFF, HC, T2D, and AD patients were performed by using Kruskal-Wallis test, while the comparison between ApoE4+ and ApoE4AD patients was performed by Mann-Whitney test. The Bonferroni correction was applied. The relationships between each mitokine levels and age were calculated by Spearman rank correlation test and regression analysis. A regression analysis was performed for $\mathrm{HC}$ and T2D to evaluate the relationship between BMI and FGF21. The difference between the two regression curves was estimated by the following linear model:

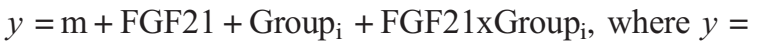
BMI values, FGF21 = covariate effect of FGF21, and Group $_{\mathrm{i}}=$ fixed effect of the $i$ th group (HC, T2D). Mediation analysis was performed using model 4 of the PROCESS Macro for SPSS with a bootstrapping procedure involving 10,000 re-samples to generate model estimates and confidence intervals.

A multinomial logistic regression model using the enter method was constructed to identify factors associated with the presence of T2D. Model fit was assessed using the Hosmer-Lemeshow goodness-of-fit test. The proportion of variance explained by the final model was determined using the Nagelkerke $R^{2}$ statistic.

Analysis of covariance (ANCOVA) followed by post-hoc tests for multiple comparisons was used to compare the mean differences in mitokine levels after adjustment for age and sex, and, in case of T2D, glucose-lowering treatment (see the "Results" section).

Receiver operating characteristics (ROC) curves were constructed to assess the discriminatory ability of mitokines in T2D complications. Youden's index was used to calculate the best cut-off values, where appropriate. Multiple ROC curves were compared using the DeLong method [41] (DeLong et al. 1988).

Significance was accepted as $p<0.05$. Data are expressed as mean $\pm \mathrm{SE}$ or SD. All data were analyzed using the SPSS 23.0 for Windows software (SPSS Inc.; Chicago, IL, USA).

\section{Results}

The plasma levels of mitokines are disease-specific

We measured the levels of GDF15, FGF21, and HN in 569 plasma samples from T2D patients, with (T2DC) or without (T2DnC) complications, AD patients, healthy age-matched controls (HC), and centenarians' offspring (OFF), see Table 1. A comparison of the plasma levels of each mitokine among all groups was performed. In agreement with our previous data [5], no gender difference was found (data not shown); therefore, males and females were pooled together.

GDF15 levels were significantly higher in T2D patients as a whole when compared to $\mathrm{HC}$, OFF and $\mathrm{AD}$ patients $(p<0.0001)$. Moreover, within T2D patients, T2DC showed higher levels with respect to T2DnC $(p<0.01)$. As far as AD patients, their levels of GDF15 were slightly but significantly higher with respect to OFF ( $p=0.012$ ), but not to HC (Fig. 1a). This last result suggests that $\mathrm{AD}$ is not associated with dramatic alterations of GDF15 concentrations at systemic level.

A different trend was observed for FGF21. In this case, OFF showed the highest levels of FGF21 as compared to all the other groups. No difference was found between $\mathrm{HC}$ and T2D or AD patients; however, a slight but significant difference was found between $\mathrm{T} 2 \mathrm{D}$ and $\mathrm{AD}$ patients (T2DnC vs $\mathrm{AD} p=$ 0.002 , and T2DC vs AD $p=0.02$ ) (Fig. 1b). These results suggest that elevated levels of FGF21 are associated with health, while low levels are more likely to be present in people with neurodegenerative problems.

Plasma levels of $\mathrm{HN}$ were significantly lower in $\mathrm{AD}$ patients with respect to all the other groups. No significant difference between healthy subjects (OFF and HC) and T2D patients was observed (Fig. 1c).

Taken together, these data suggest that these mitokines are modulated in a disease-specific way. 

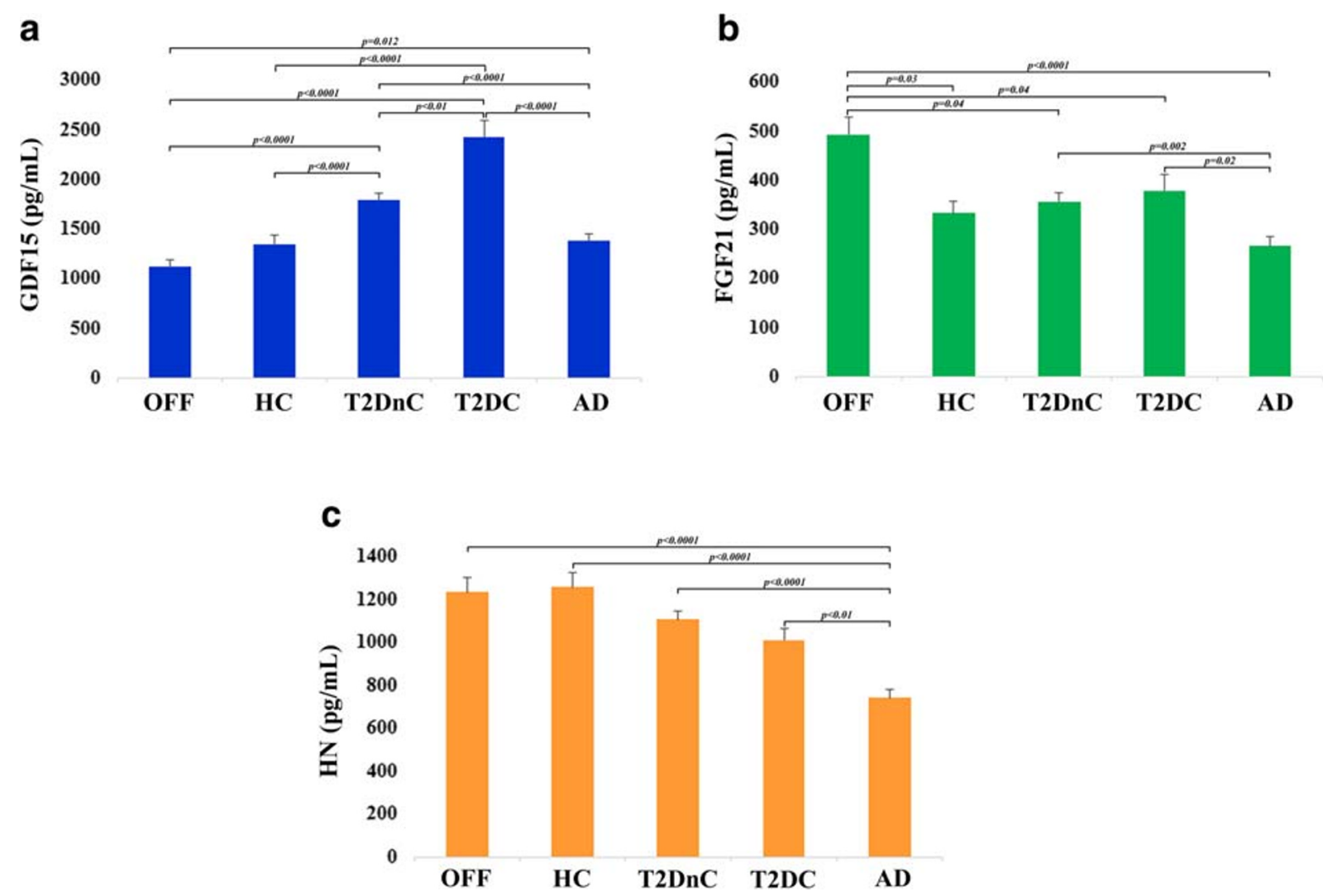

Fig. 1 Plasma levels of GDF15, FGF21 and HN in healthy and pathological conditions. Circulating plasma levels of GDF15 (a), FGF21 (b), and HN (c) in centenarians' offspring (OFF), healthy controls (HC), T2D patients without complications (T2DnC) and

As far as the levels of FGF21 in T2D patients, our results are in apparent contrast with literature data showing that T2D patients are characterized by higher levels of FGF21 as compared to controls [42-44]. However, since FGF21 is influenced by BMI [44], and BMI is often higher in T2D patients than control subjects [45], we have hypothesized that the relationship between FGF21 and T2D can be mediated by BMI. To confirm this idea, we first divided HC and T2D patients in three subgroups according to their BMI (normal weight, overweight, and obese) and we observed that the levels of FGF21 were similar between HC and T2D in each BMI subgroup, while FGF21 levels were significantly higher in overweight and obese subjects with respect to normal weight group in both $\mathrm{HC}$ and T2D (Table 2). To further confirm these data, we then performed a regression analysis. A positive association between BMI and FGF21 concentrations is present; however, the two regression lines referred to as $\mathrm{HC}$ and $\mathrm{T} 2 \mathrm{D}$ are not
T2D patients with complications (T2DC), and Alzheimer's disease patients (AD). Data are expressed as mean \pm SE. $p$ values were determined by Kruskal-Wallis test with Bonferroni correction

significantly different, confirming that FGF21 is influenced by BMI but not T2D (Fig. 2).

Plasma levels of mitokines increase with age

We have previously reported that mitokine plasma levels increase with age in healthy people, from young to centenarians, and are correlated with worst hematochemical parameters, including lipid profile [5]. We then sought to check whether the age-related increase is confirmed in a narrower age range. Moreover, since in that previous study the participants were healthy subjects, we wondered whether similar changes of mitokines were present also in patients with $\mathrm{T} 2 \mathrm{D}$ or AD. Plasma levels of GDF15, FGF21, and HN were all positively and significantly correlated with age in healthy subjects (data not shown), confirming previous results [5]. At variance, when looking at patients (T2D and $\mathrm{AD}$ pooled together), $\mathrm{HN}$ resulted strongly 
Table 2 Circulating levels of FGF21 in healthy controls (HC) and T2D patients subdivided by BMI. The comparison is shown between $\mathrm{HC}$ and T2D within the same BMI subgroup ( $p$ values reported on the right, Mann-Whitney test) and among the different BMI subgroups ( $p$ values reported below, Kruskal-Wallis test). Data are expressed as mean values \pm standard error (SE). Significance level of $p$ value is $<0.05$. n.s., not significant

\begin{tabular}{|c|c|c|c|}
\hline \multirow[t]{2}{*}{ Mean $\pm \mathrm{SE}$} & \multicolumn{3}{|c|}{$\begin{array}{l}\text { Normal weight } \\
\text { (BMI range: } 18.5 \text { to } 24.99 \text { ) }\end{array}$} \\
\hline & $\mathrm{HC}\left(n^{\circ}=22\right)$ & $\mathrm{T} 2 \mathrm{D}\left(n^{\circ}=40\right)$ & $p$ value \\
\hline BMI & $23.16( \pm 0.35)$ & $23.16( \pm 0.35)$ & \\
\hline FGF21 $(\mathrm{pg} / \mathrm{mL})$ & $258.32( \pm 35.50)$ & $286.59( \pm 33.88)$ & n.s. \\
\hline \multirow[t]{2}{*}{ Mean \pm SE } & \multicolumn{3}{|c|}{$\begin{array}{l}\text { Overweight } \\
\text { (BMI range: } 25 \text { to } 29.99 \text { ) }\end{array}$} \\
\hline & $\mathrm{HC}\left(n^{\circ}=49\right)$ & $\mathrm{T} 2 \mathrm{D}\left(n^{\circ}=123\right)$ & $p$ value \\
\hline BMI & $27.41( \pm 0.20)$ & $27.27( \pm 0.12)$ & \\
\hline FGF21 (pg/mL) & $349.20( \pm 40.66)$ & $352.23( \pm 28.35)$ & n.s. \\
\hline Mean \pm SE & $\begin{array}{l}\text { Obese } \\
\quad(\mathrm{BMI}>30) \\
\quad \mathrm{HC}\left(n^{\circ}=21\right)\end{array}$ & $\mathrm{T} 2 \mathrm{D}\left(n^{\circ}=92\right)$ & $p$ value \\
\hline BMI & $33.45( \pm 0.89)$ & $33.71( \pm 0.32)$ & \\
\hline \multirow[t]{2}{*}{ FGF21 (pg/mL) } & $377.72( \pm 29.12)$ & $412.95( \pm 22.42)$ & n.s. \\
\hline & $\begin{array}{c}p \text { value } \\
0.03\end{array}$ & $\begin{array}{l}p \text { value } \\
<0.001\end{array}$ & \\
\hline
\end{tabular}

associated with age, as well as GDF15, although more weakly, but not FGF21 (data not shown). However, when we performed the regression analysis considering the subjects divided by groups (HC, OFF, T2DnC, $\mathrm{T} 2 \mathrm{DC}, \mathrm{AD})$, the correlation with age was not always confirmed. GDF15 plasma levels were associated with age in OFF and $\mathrm{HC}$, as well as in $\mathrm{AD}$ patients (Fig. 3a, c), but not in T2D patients (Fig. 3b). FGF21 plasma levels resulted associated with age only in OFF (Fig. 3a). HN plasma levels resulted associated with age in $\mathrm{HC}, \mathrm{T} 2 \mathrm{DnC}$, and $\mathrm{AD}$ patients (Fig. 3a-c). Interestingly, no mitokine resulted associated with age in T2DC patients (Fig. 3b). This could be due to the excess fractionation into small groups, or to the presence of a disease that can overwhelm the effect of age, as already observed for the levels of circulating miR-146a in T2D patients [39].

\section{Mitokines in T2D patients}

After adjusting for age and gender, mitokines in T2D patients were analyzed in relation to the type of treatment, i.e., no treatment (NoT), metformin (Met), sulphonylureas (Sulph), combination of metformin and
Fig. 2 Regression analysis of FGF21 plasma levels with BMI. a Linear regression analysis of two different groups: healthy controls (HC) and T2D patients. b Comparison between the two regression curves. DF, degrees of freedom; Group: effect of the $i$ th group (HC, T2D)

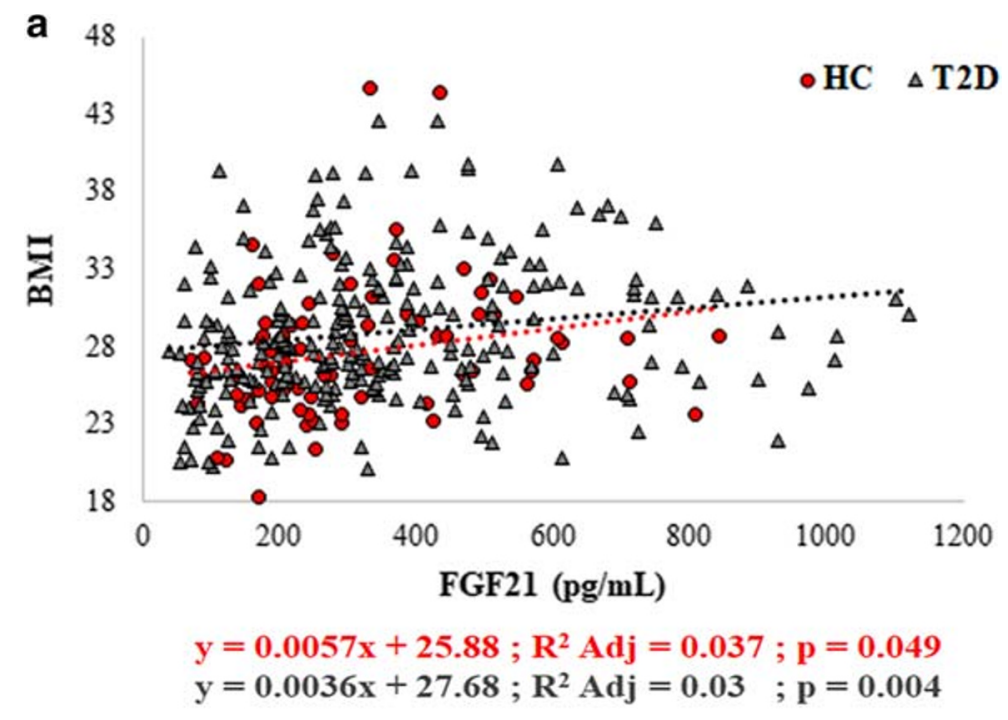

b

\begin{tabular}{l|c|c|c|c} 
Source & DF & Sum of Squares & F Ratio & Prob $>$ F \\
FGF21 & 1 & 166.11 & $\$ .69$ & 0.003 \\
\hline Group & 1 & 75.99 & 3.97 & 0.047 \\
\hline FGF21*Group & 1 & 7.45 & 0.39 & 0.532
\end{tabular}


a

Healthy subjects: $\bullet \mathrm{OFF}-\bullet \mathrm{HC}$

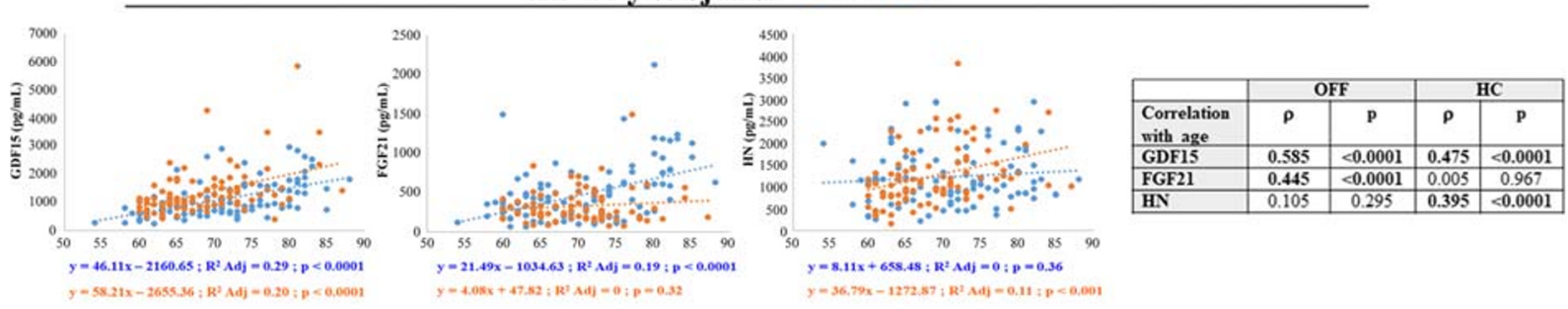

b

T2D patients: - T2DnC - - T2DC

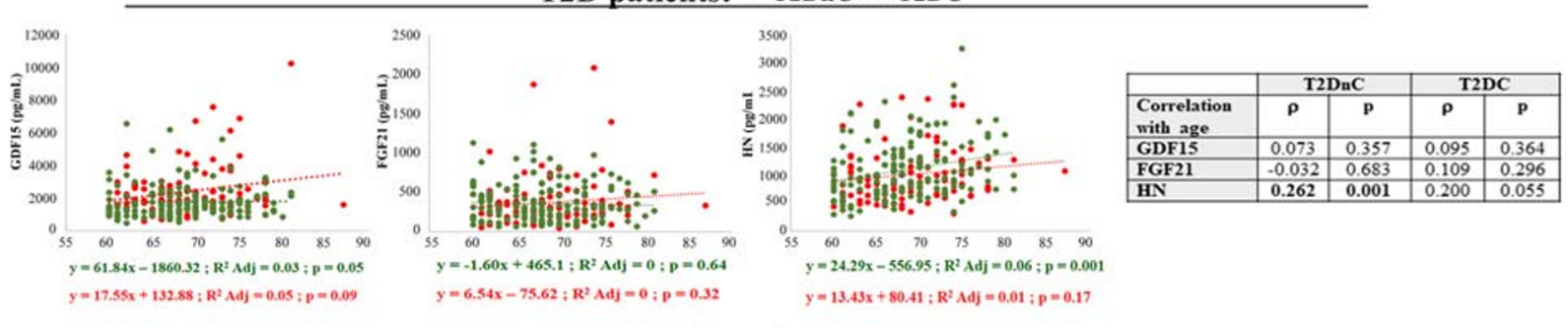

c

-AD patients
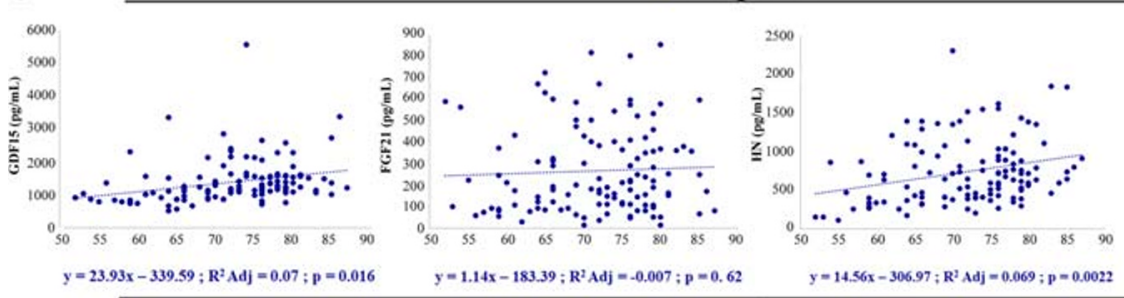

AGE

Fig. 3 Regression analysis of GDF15, FGF21, and HN plasma levels with age. Linear regression and Spearman rank correlation analysis $(\rho)$ between age and GDF15, FGF21, and HN in centenarians' offspring (OFF) and healthy controls (HC) (a),
T2D patients without complications (T2DnC) and T2D patients with complications (T2DC) (b), and Alzheimer's disease patients (AD) (c)

patients on the basis of the triglycerides/HDL (TG/ HDL) ratio, known to be associated to insulin resistance and cardiovascular disease in T2D [49, 50]. We found that patients with high TG/HDL ratio have higher level of GDF15 and FGF21 (Supplementary Table 1). At variance, the presence of lipid lowering therapy, antihypertensive therapy, or both, does not impact on mitokines levels (data not shown).

As far as T2D complications, the presence of a complication resulted often associated with a higher level of GDF15 (Table 3), also after adjusting for age, gender, and treatment. This result is in agreement with previous literature data [27, 51]. FGF21 resulted more elevated in presence of nephropathy or cardiac ischemia. Interestingly, for $\mathrm{HN}$ the situation was less linear: higher $\mathrm{HN}$ levels were found in presence of chronic kidney disease, while lower levels were found in presence of retinopathy and, in general, of at least one complication 
a

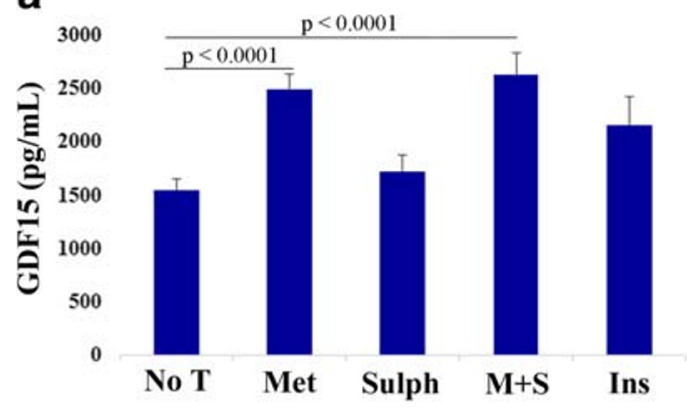

b

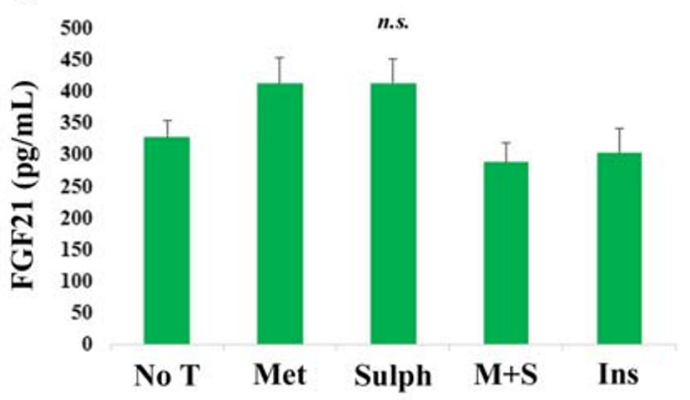

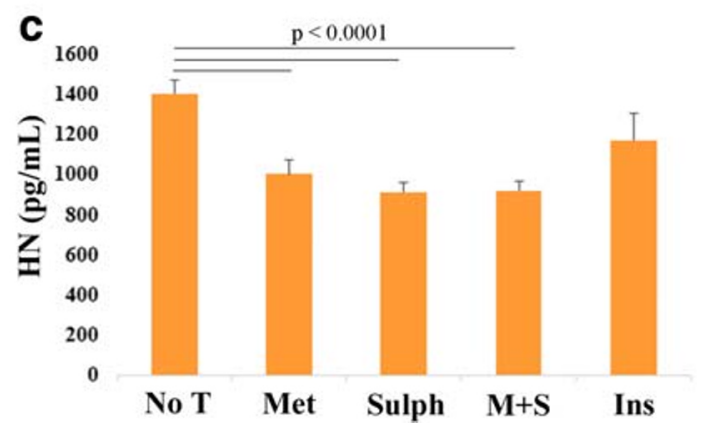

Fig. 4 Plasma levels of GDF15, FGF21 and HN in T2D patients with different antidiabetic treatments. Comparison of circulating plasma levels of GDF15 (a), FGF21 (b), and HN (c) in T2D patients undergoing the following treatments: no treatment (No

(Table 3). Moreover, only the plasma levels of GDF15 were significantly correlated with the number of complications (Spearman rank correlation coefficient and $p$ value: rho $=0.265, p<0.001$ ).

Since the levels of the three mitokines were higher in T2D patients with at least one complication, a binary regression analysis was performed to estimate the odds ratio (OR) and $95 \%$ confidence interval (CI) of mitokines for predicting the presence of diabetic complications. In addition to mitokines, age, gender, and serum $\mathrm{HbAlc}$ were included in this model as covariates, as it is well known that glycemic control is closely associated with the onset of complications [52, 53]. Binary logistic analysis showed that among mitokines, only GDF15 was independently associated with diabetic complications (Table 4). Remarkably, the association remained significant despite rigorous adjustment for conventional disease-related variables.

To evaluate the discriminative ability of GDF15 for the presence of complications, we calculated the receiver operating characteristic curve (ROC) analysis and compared with that of HbA1c (Fig. 5). The AUCs for GDF15 and HbA1c were $0.632(p<0.001)$ and 0.703
T), metformin (Met), sulphonylureas (Sulph), combination of metformin and sulphonylureas $(\mathrm{M}+\mathrm{S})$, and insulin (Ins). Data are expressed as mean \pm SE. $p$ values were determined by Kruskal-Wallis test with Bonferroni correction

$(p<0.001)$, respectively. When combined together, GDF15 and HbA1c gave an AUC value of $0.747(p<$ 0.001 ), which is significantly larger than those for the two separated parameters (HbA1c + GDF15 versus HbA1c, $p=0.013$; HbA1c + GDF15 versus GDF15, $p=0.003$ ) (Fig. 5). Taken together, these results indicated that GDF15 could significantly improve the reliability of HbA1c in the assessment of glycemic control and in the diagnosis of T2D complications.

Recent data suggest that GDF15 can be a risk predictor of kidney function decline [24]. Besides, we have observed that high levels of mitokines correlated with nephropathy/chronic kidney disease (Table 3), as well as with levels of creatinine and estimated glomerular filtration rate (eGFR) (Table 5). We therefore tested the hypothesis that the effect of mitokines on kidney function could be mediated by other variables. The mediation analysis was performed testing several variables known to be linked to kidney disease, including Creactive protein, IL-6, uric acid, azotemia, triglycerides, ApoA1, ApoB, and $\mathrm{HbA1c}$, and that resulted associated with mitokines, (data not shown). Results indicate that FGF21 and HN have an independent effect on eGFR, 


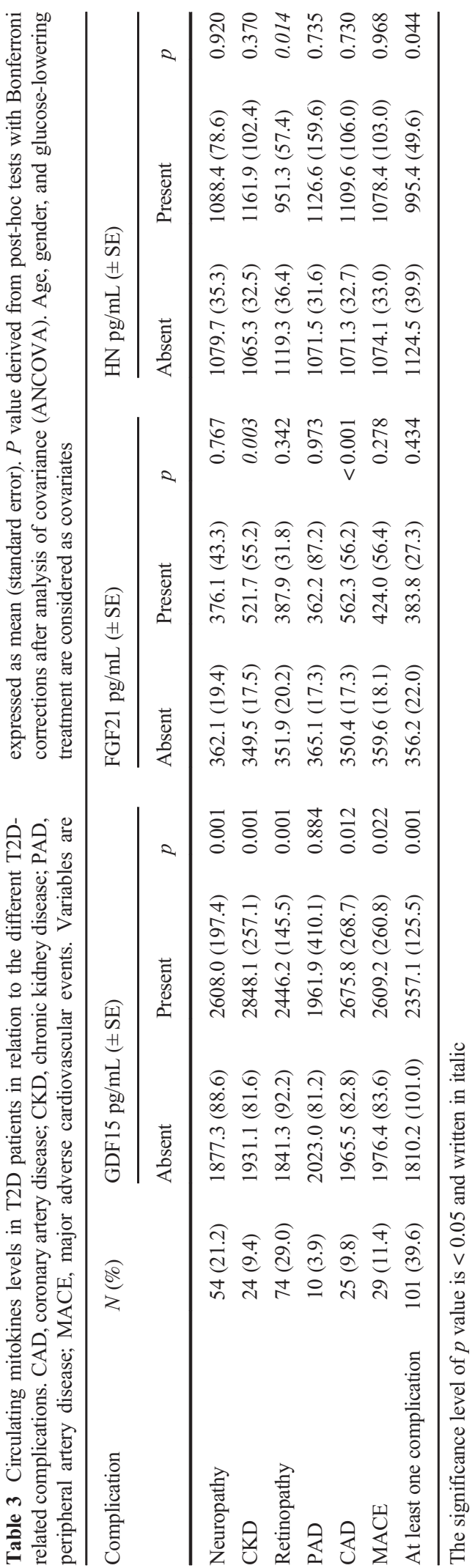

while the $22 \%$ of the effect of GDF15 on eGFR was mediated by uric acid $(-0.98 /-4.37=22.4 \%)$ (Fig. 6).

Mitokines and ApoE genotype

As described above, AD but not T2D patients show lower plasma levels of $\mathrm{HN}$ as compared to $\mathrm{HC}$ and OFF, while a specular situation is found for GDF15: $\mathrm{T} 2 \mathrm{D}$ but not $\mathrm{AD}$ patients have higher levels as compared to $\mathrm{HC}$ and OFF. Finally, a difference exists between T2D and AD patients as far as FGF21 (Fig. 1). This suggests that despite a tight metabolic connection between $\mathrm{AD}$ and $\mathrm{T} 2 \mathrm{D}[9,10]$, a clear difference exists as far as mitokine expression pattern in these two pathologic conditions. ApoE4 allelic variant is a universally recognized risk for sporadic $\mathrm{AD}$ and affects mitochondrial function, energy, and lipid metabolism in $\mathrm{AD}$ patients [54-56]. So far, no data are available as far as the association between ApoE4 and mitokines. We therefore investigated the possible association between ApoE4 allele and the levels of mitokines. ApoE genotypes for the majority of subjects (AD and T2D patients, part of HC) were available and are shown in Supplementary Table 2 . When looking at all subjects pooled together (HC, T2DnC, T2DC, and AD), only for HN we found a slight difference between ApoE4 carriers and non-carriers. In particular, HN levels were lower in ApoE4+ subjects compared to ApoE4- ones ( $p=0.04$, data not shown). However, when we performed the same analysis considering the subjects divided by groups, no difference in the levels of the three mitokines was observed between ApoE4 carriers and non-carriers (Fig. 7).

\section{Discussion}

The mainstream interpretation of the biological role of mitokines is that they may help tissues, organs, and eventually the whole organisms in coping with stresses by mediating metabolic adaptation in response to an energy crisis produced by mitochondrial dysfunction $[5,6,57]$. However, many findings indicate that high circulating levels of GDF15, FGF21, and HN are associated not only with beneficial response to mitochondrial dysfunction but also with aging and several agerelated diseases to the point that they are often considered useful diagnostic markers [6, 58-60]. In agreement with this tenet, in our previous studies, we have shown 
Table 4 Binary logistic regression analyses of variables contributing to diabetic complications ( $\mathrm{M}=$ male). The logistic regression model is statistically significant $(\chi 2(4)=90.838, p<0.0001)$, explains $33.4 \%$ of the total variance (Nagelkerke $R^{2}$ ) and correctly classifies $76.0 \%$ of cases. The Odds ratio of mitokines refers to the increased probability to have a complication per every $100 \mathrm{pg} / \mathrm{mL}$ of mitokines. $P$ value derived from post-hoc tests with Bonferroni corrections after analysis of covariance (ANCOVA). Age and gender are considered as covariates

\begin{tabular}{llllllr}
\hline Parameters & B & SE & Wald & Odds ratio & 95\% CI for Odds ratio & p value \\
\hline Gender (M) & 0.742 & 0.285 & 6.803 & 2.101 & $1.203-3.670$ & 0.009 \\
Age & 0.057 & 0.026 & 4.928 & 1.059 & $1.007-1.114$ & 0.026 \\
HbA1c & 0.923 & 0.141 & 42.760 & 2.518 & $1.909-3.321$ & 0.001 \\
GDF15 & 0.027 & 0.012 & 4.639 & 1.027 & $1.002-1.053$ & 0.031 \\
FGF21 & -0.026 & 0.052 & 0.256 & 0.974 & $0.880-1.079$ & 0.613 \\
HN & -0.056 & 0.030 & 3.545 & 0.945 & $0.891-1.002$ & 0.060 \\
\hline
\end{tabular}

The significance level of $p$ value is $<0.05$ and written in italic

that these mitokines increase with age and are particularly elevated in centenarians, as well as in subjects that presented worse values of biochemical parameters, including insulin resistance (HOMA-IR), lipid profile, and inflammation [5, 24]. However, it is not clear whether different age-associated diseases characterized by mitochondrial dysfunction display similar patterns of mitokine expression. To this regard, we focused on two very common age-related diseases, $\mathrm{T} 2 \mathrm{D}$ and $\mathrm{AD}$, for which several studies suggested that insulin resistance and mitochondrial dysfunction could be the common denominators [61, 62]. T2D is a devastating disease, causing excessive rates of cardiovascular disease, renal disease, eye diseases, and many neurological problems. $\mathrm{AD}$ itself has been recently proposed as an additional complication of T2D $[8,63]$. This idea is supported by evidence indicating that the decrease of glucose metabolism caused by insulin resistance results in stress at
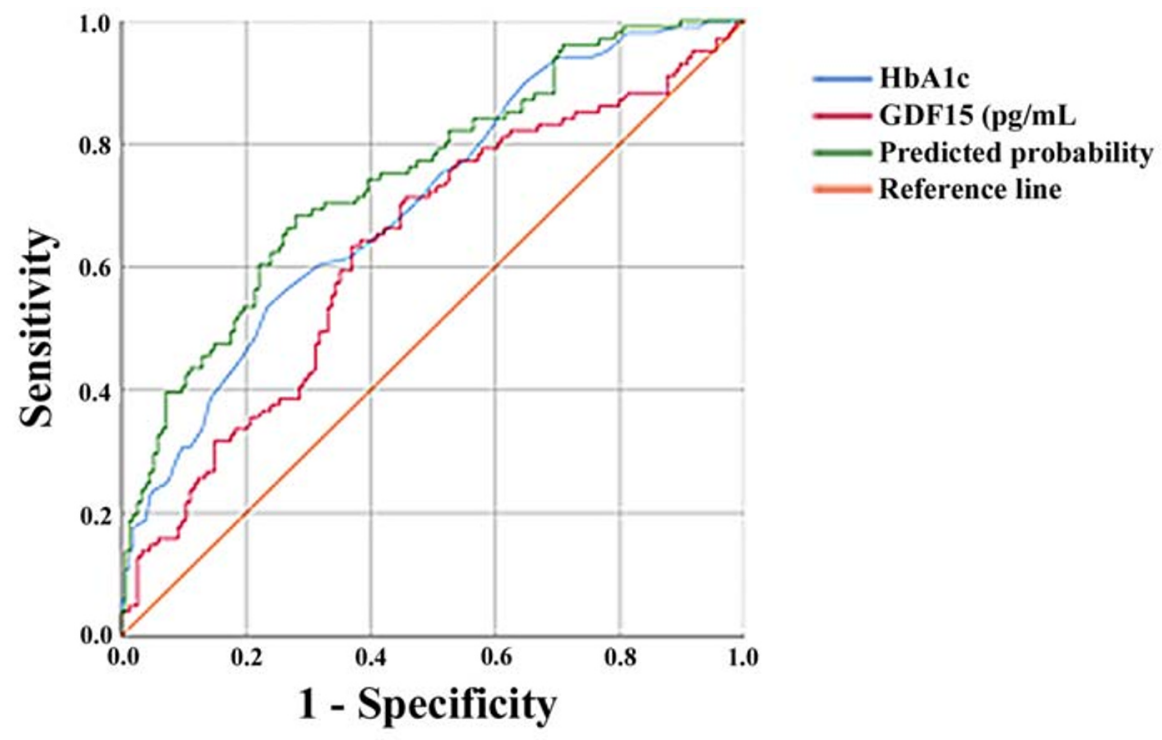

\begin{tabular}{lll|l|l}
\hline ROC Curre & AUC & SE & P & Cutoff(Youden) \\
\hline 1) HbAlc & 0.703 & 0.033 & $<0.001$ & $>7.6 \%(\mathrm{SE}=44.3 \%, \mathrm{SP}=73.4 \%, \mathrm{PPV}=66.5 \%, \mathrm{NPV}=52.5 \%)$ \\
2) GDF15 & 0.632 & 0.036 & $<0.001$ & $>1712.5 \mathrm{pg} \mathrm{m} 1(\mathrm{SE}=63.4 \%, \mathrm{SP}=63.0 \%, \mathrm{PPV}=52.9 \%, \mathrm{NPV}=72.4 \%)$ \\
\hline 3) HbA1c + GDF15 & 0.747 & 0.031 & $<0.001$ & $\mathrm{n} / \mathrm{a}$ \\
\hline
\end{tabular}

Fig. 5 Receiver operating characteristic (ROC) curves for GDF15 and hemoglobin A1c (HbA1c) in T2D patients with complications. Comparison of ROC analysis of GDF15, HbA1c, and
GDF15 + HbA1c. GDF15 and HbA1c together gave a value of area under the ROC curve (AUC) larger than those of the two parameters analyzed separately 
Table 5 Spearman rank correlation coefficient and $p$ values for the correlations between circulating mitokines and renal function, expressed as serum creatinine and eGFR, in T2D patients

\begin{tabular}{llrlrr}
\hline Correlations & \multicolumn{2}{l}{ Creatinine } & & eGFR & \\
\cline { 2 - 3 } \cline { 5 - 6 } & $\rho$ & $p$ value & & $\rho$ & $p$ value \\
\hline GDF15 & 0.461 & $<0.001$ & & -0.301 & $<0.001$ \\
HN & 0.323 & $<0.001$ & & -0.318 & $<0.001$ \\
FGF21 & 0.209 & 0.001 & & -0.163 & 0.009 \\
\hline
\end{tabular}

mitochondrial level, leading to apoptosis of neurons and neuroinflammation [61, 62].

In the present study, we compared the plasma levels of GDF15, FGF21, and $\mathrm{HN}$ in T2D and AD patients as compared to healthy subjects, including centenarians' offspring (OFF) who are reported to be in a better health status as compared to age-matched peers $[35,36]$, and we observed a differential expression pattern of these mitokines at circulating level. Based on previous studies $[5,6]$ and literature data (in particular for GDF15), we were expecting that patients would display higher levels of mitokines with respect to healthy controls. In contrast with these expectations, the results showed a more complex situation. In particular, circulating GDF15 levels were higher in $\mathrm{T} 2 \mathrm{D}$ patients but not in $\mathrm{AD}$ ones, FGF21 levels were elevated in OFF and lower in AD but not in T2D patients, and HN levels were lower in both T2D and AD patients, particularly in the latter. Moreover, we observed a significant association of all three mitokines with age only in healthy subjects, while in $\mathrm{T} 2 \mathrm{D}$ and $\mathrm{AD}$ patients this association appears to be not always present. Consistently, mitokines correlated with each other only in OFF and $\mathrm{HC}$, but not in patients (data not shown). These results suggest that, when considering healthy subjects, age is a determinant of mitokine increase, while when considering subjects of similar age range but different health status, the level of the three mitokines, and in particular GDF15 and FGF21, may greatly vary.

Regarding T2D, all the three mitokines showed interesting associations with the presence of complications and they were related to worsening eGFR. In particular, while confirming literature data indicating that GDF15 increases in T2D [27, 64], our results indicate that GDF15 improves the ability of the conventional marker $\mathrm{HbAlc}$ in diagnosing patients with complicated T2D. To this regard, the identification of novel biomarkers capable of predicting the development of complications and the decline of renal function in patients with T2D is a timely issue.

Conversely, for FGF21, we did not observe any association with T2D. As mentioned in the "Results" section, literature data indicate that the levels of FGF21 are significantly higher in patients with T2D with respect to healthy controls [42-44]. However, FGF21 is strongly related to obesity [17], and we have observed that, when stratified for BMI, T2D patients and healthy controls have the same level of FGF21, suggesting that the reported association of FGF21 with T2D is likely mediated by BMI. In any

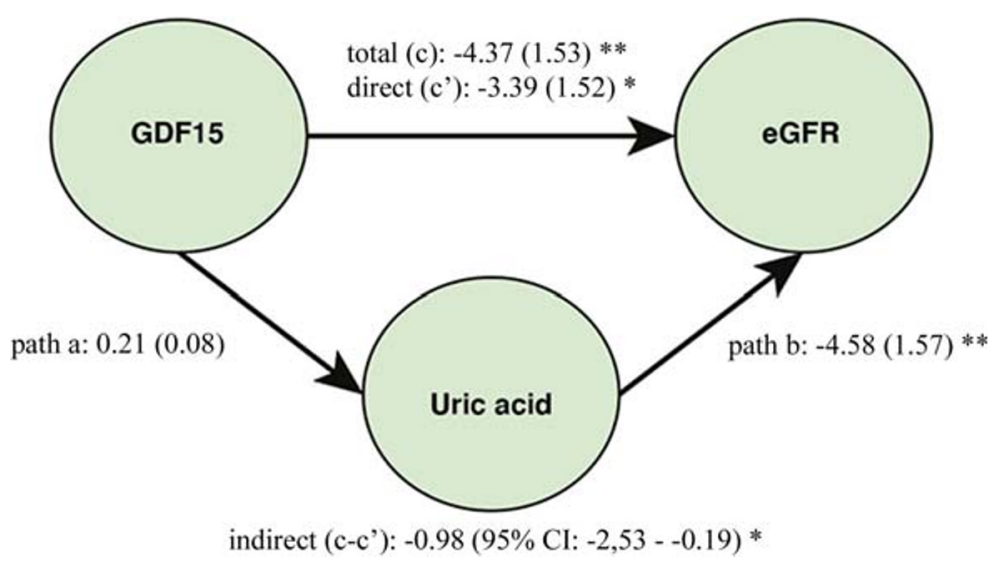

Fig. 6 Conceptual framework of the mediation analysis. Direct acyclic graph showing the association between GDF15 and estimated glomerular filtration rate (eGFR), where uric acid was considered as mediator. $* p<0.05$; $* * p<0.01$ for standardized bootstrapped (10,000 samples) total, direct and indirect effect size. In brackets, the standard errors for total and direct effects and the 95\% CI for indirect effect are reported. The mediation procedure is described in the "Material and methods" section 
Fig. 7 Plasma levels of GDF15, FGF21, and $\mathrm{HN}$ in ApoE4 Circulating plasma levels of GDF15 (a), FGF21 (b), and HN (c) in healthy controls (HC), T2D patients without complications (T2DnC) and T2D patients with complications (T2DC), and Alzheimer's disease patients (AD) divided by ApoE4 carriers and non-carriers subgroups. Data are expressed as mean $\pm \mathrm{SE}$ carriers and non-carriers subjects.

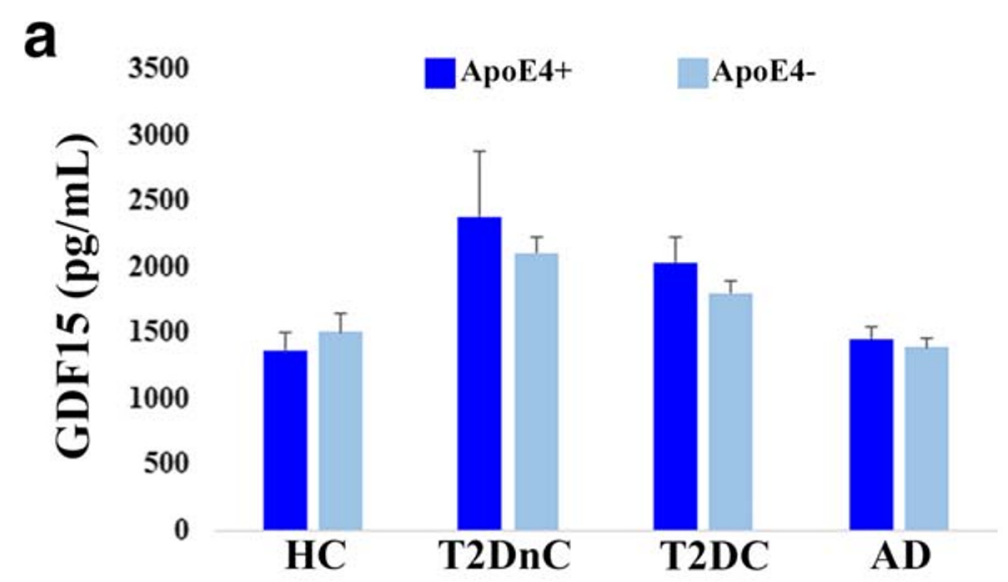

b

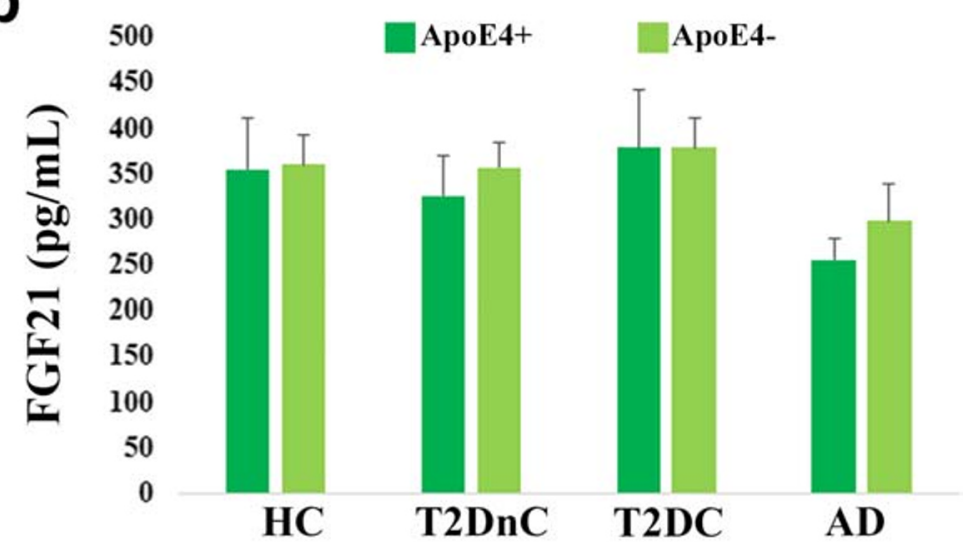

C

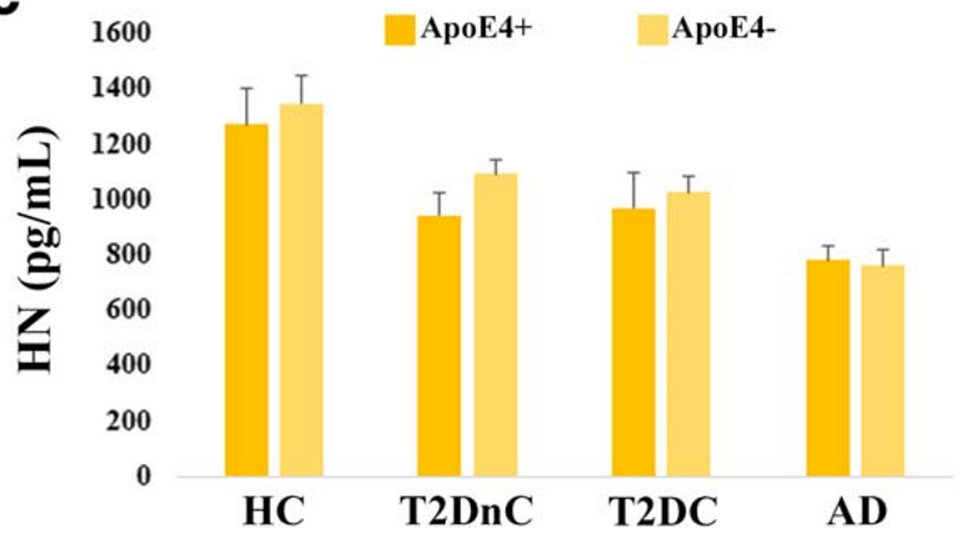

case, the association of FGF21 with BMI and obesity appears to be paradoxical, since it has been demonstrated that FGF21 overexpression or administration prevents diet-induced obesity and insulin resistance $[65,66]$. It is possible that the secretion of FGF21 in overweight people is an adaptive attempt trying to control weight gain [67].

As far $\mathrm{HN}$ and $\mathrm{T} 2 \mathrm{D}$, we did not observe a strong association between them; however, the levels of $\mathrm{HN}$ tended to be lower in $\mathrm{T} 2 \mathrm{D}$ patients compared to $\mathrm{HC}$, 
although not significantly after Bonferroni correction. The possible role of $\mathrm{HN}$ in T2D is still unclear, and to date, there are still few studies on $\mathrm{HN}$ in diabetes. In particular, Voigt and Jelinek showed that the plasma levels of $\mathrm{HN}$ are lower in prediabetic patients with impaired fasting glucose compared to a control group [68], and similarly, Ramanjaneya and co-workers demonstrated that serum $\mathrm{HN}$ concentration was lower in $\mathrm{T} 2 \mathrm{D}$ and negatively correlated with $\mathrm{HbA} 1 \mathrm{c}$ and glucose [69]. In agreement, in our study, we also found a negative correlation of $\mathrm{HN}$ with HbA1c (spearman's rho = $-0.305, p<0.0001$ ) and glycemia (spearman's rho $=$ $-0.291, p<0.0001$ ), suggesting that HN could be involved in the maintenance of insulin sensitivity. Taken together, these data suggest that GDF15 and HN are involved in the response to diabetic stress with an opposite regulation, while FGF21 appears to be affected by BMI but not T2D.

Concerning $\mathrm{AD}$, limited data are available on the association between GDF-15 and neurodegenerative diseases. In our study, the levels of GDF15 in AD patients were similar to those of healthy controls. Some studies reported that higher levels of GDF-15 (plasma, serum, or cerebrospinal fluid) are associated with cognitive impairment and dementia, as well as with decreased gray matter volumes and white matter integrity. All these data suggest that GDF15 could be a possible biomarker for neurodegenerative diseases [70-72]. However, none of these studies described the levels of GDF15 for AD patients, but rather for Parkinson's disease or Lewy Body Dementia. Thus, GDF15 plasma levels may be associated to some neurodegenerative diseases, but not to AD.

As far as FGF21 in AD patients, it has been reported that higher levels of FGF21 have beneficial effects in several pathologies, including neurodegenerative diseases, although the biological function of FGF21 on $\mathrm{AD}$ is still largely unclear. To this regard, an in vitro and in vivo study reported that FGF21 attenuated the negative effects of amyloid $\beta$-peptide $25-35$ on neuronal apoptosis, tau hyperphosphorylation, and oxidative stress in AD-like pathologies [73]. In agreement with these data, we found that FGF21 circulating levels in $\mathrm{AD}$ are lower with respect to the other groups, in particular to OFF. Interestingly, we recently reported that post-menopausal women suffering by chronic insomnia, a condition known to be a risk factor for the development of $\mathrm{AD}$ [74], display lower levels of FGF21 as compared with age-matched women without sleep disorders [75]. This result further supports the idea that FGF21 plays important roles in neurophysiology.

As far as $\mathrm{HN}$ in $\mathrm{AD}$, our results confirm literature data indicating that $\mathrm{HN}$ decreases in $\mathrm{AD}$ [76-78]. In our samples, HN was, in fact, lower in AD patients with respect to healthy controls. Interestingly, although several studies showed a decrease of HN with aging, our results showed a strong positive correlation of $\mathrm{HN}$ with age in $\mathrm{AD}$ patients. This suggests that the mechanisms that impinge upon $\mathrm{HN}$ production are different and independent in $\mathrm{AD}$ and aging. Moreover, we did not find any difference between $\mathrm{OFF}$ and $\mathrm{HC}$, at variance with a recently published study [79]. To this regard, it is to note that the authors of this study reported very low levels of HN for both OFF and HC (around $500 \mathrm{pg} / \mathrm{ml}$ and $200 \mathrm{pg} / \mathrm{ml}$, respectively) that are much lower than expected according to previous studies $(1200 \mathrm{pg} / \mathrm{ml}$ or higher) $[32,74,80,81]$. Moreover, they used an inhouse kit for the detection of $\mathrm{HN}$, while we used a commercially available one (see the "Materials and methods" section), so the two studies are likely not comparable. Further investigations are needed to clarify this point.

As a whole, our results suggest that GDF15, FGF21, and HN may act synergistically only during physiological aging in the absence of overt diseases. Conversely, when a disease occurs, their expression is modulated differently, even though the considered diseases share a common ground of mitochondrial impairment, like T2D and AD. More studies are needed to clarify the mechanisms underlying this differential modulation.

Author contributions M.C. is responsible for the data generation and collection, statistical analysis, and writing of the manuscript. J.S. did the statistical analysis and manuscript revision. A.C. and M.M. contributed in the analysis of mitokines. A.S., D.M., D.G., E.S., and F.O. did the sample data retrievement and manuscript revision. A.G., A.R.B., and M.A. did the biobank management. C.F. provided the study design and critical discussion. S.S. took part in the study design, analysis of the data, and writing of the manuscript.

Funding Open access funding provided by Alma Mater Studiorum - Università di Bologna within the CRUI-CARE Agreement. The study was partially supported by the Roberto and Cornelia Pallotti Legacy for Cancer Research to S.S.; worldclass scientific center - the Center for Photonics, created within the framework of the Russian National Project "Science" to C.F.; the Italian Ministry of Health Ricerca Finalizzata Young Researchers (under 40)-Giovani Ricercatori (GR-2013-02358026) and the JPIHDHL-Metadis, "EURODIET" project (ID: 1164; 2020-2023) to A.S.; and the Italian Ministry of Health (Ricerca Corrente) to E.S. 


\section{Compliance with ethical standards}

Conflict of interest The authors declare that they have no conflict of interest.

Open Access This article is licensed under a Creative Commons Attribution 4.0 International License, which permits use, sharing, adaptation, distribution and reproduction in any medium or format, as long as you give appropriate credit to the original author(s) and the source, provide a link to the Creative Commons licence, and indicate if changes were made. The images or other third party material in this article are included in the article's Creative Commons licence, unless indicated otherwise in a credit line to the material. If material is not included in the article's Creative Commons licence and your intended use is not permitted by statutory regulation or exceeds the permitted use, you will need to obtain permission directly from the copyright holder. To view a copy of this licence, visit http://creativecommons.org/licenses/by/4.0/.

\section{References}

1. Franceschi C, Garagnani $\mathrm{P}$, Morsiani C, et al. The continuum of aging and age-related diseases: common mechanisms but different rates. Front Med (Lausanne). 2018;5:61. https://doi.org/10.3389/fmed.2018.00061.

2. Chen G, Kroemer G, Kepp O. Mitophagy: an emerging role in aging and age-associated diseases. Front Cell Dev Biol. 2020;8:200. https://doi.org/10.3389/fcell.2020.00200.

3. Natarajan V, Chawla R, Mah T, Vivekanandan R, Tan SY, Sato PY, et al. Mitochondrial dysfunction in age-related metabolic disorders. Proteomics. 2020;20:e1800404. https://doi.org/10.1002/pmic.201800404.

4. Durieux J, Wolff S, Dillin A. The cell-non-autonomous nature of electron transport chain-mediated longevity. Cell. 2011;144:79-91. https://doi.org/10.1016/j.cell.2010.12.016.

5. Conte M, Ostan R, Fabbri C, Santoro A, Guidarelli G, Vitale $\mathrm{G}$, et al. Human aging and longevity are characterized by high levels of Mitokines. J Gerontol A Biol Sci Med Sci. 2019;74:600-7. https://doi.org/10.1093/gerona/gly153.

6. Conte M, Martucci M, Chiariello A, et al. Mitochondria, immunosenescence and inflammaging: a role for mitokines? Semin Immunopathol. in press. https://doi.org/10.1007 /s00281-020-00813-0.

7. Jayaraman A, Pike CJ. Alzheimer's disease and type 2 diabetes: multiple mechanisms contribute to interactions. Curr Diab Rep. 2014;14:476. https://doi.org/10.1007 /s11892-014-0476-2.

8. Boccardi V, Murasecco I, Mecocci P. Diabetes drugs in the fight against Alzheimer's disease. Ageing Res Rev. 2019;54: 100936. https://doi.org/10.1016/j.arr.2019.100936.

9. Kandimalla R, Thirumala V, Reddy PH. Is Alzheimer's disease a type 3 diabetes? A critical appraisal. Biochim Biophys Acta Mol Basis Dis. 1863;2017:1078-89. https://doi.org/10.1016/j.bbadis.2016.08.018.
10. Cheng H, Gang X, Liu Y, Wang G, Zhao X, Wang G. Mitochondrial dysfunction plays a key role in the development of neurodegenerative diseases in diabetes. Am J Physiol Endocrinol Metab. 2020;318:E750-64. https://doi. org/10.1152/ajpendo.00179.2019.

11. Rigotto G, Basso E. Mitochondrial dysfunctions: a thread sewing together Alzheimer's disease, diabetes, and obesity. Oxidative Med Cell Longev. 2019;2019:7210892-16. https://doi.org/10.1155/2019/7210892. eCollection 2019. Review.

12. Zhang Y, Xie Y, Berglund ED, Coate KC, He TT, Katafuchi $\mathrm{T}$, et al. The starvation hormone, fibroblast growth factor-21, extends lifespan in mice. Elife. 2012;1:e0065. https://doi. org/10.7554/eLife.00065.

13. Salminen A, Kaarniranta K, Kauppinen A. Regulation of longevity by FGF21: interaction between energy metabolism and stress responses. Ageing Res Rev. 2017;37:79-93. https://doi.org/10.1016/j.arr.2017.05.004 Review.

14. Yu Y, He J, Li S, Song L, Guo X, Yao W, et al. Fibroblast growth factor 21 (FGF21) inhibits macrophage-mediated inflammation by activating Nrf2 and suppressing the NFKB signaling pathway. Int Immunopharmacol. 2016;38: 144-52. https://doi.org/10.1016/j.intimp.2016.05.026.

15. Jia H, Cheng J, Zhou Q, Peng J, Pan Y, Han H. Fibroblast growth factor 21 attenuates inflammation and oxidative stress in atherosclerotic rat via enhancing the Nrf1-ARE signaling pathway. Int J Clin Exp Pathol. 2018;11:1308-17.

16. Tezze C, Romanello V, Sandri M. FGF21 as modulator of metabolism in health and disease. Front Physiol. 2019;10: 419. https://doi.org/10.3389/fphys.2019.00419.

17. Zhang X, Yeung DC, Karpisek M, et al. Serum FGF21 levels are increased in obesity and are independently associated with the metabolic syndrome in humans. Diabetes. 2008;57:1246-53. https://doi.org/10.2337/db07-1476 [published correction appears in Diabetes. 2019 Jan;68 (1):235].

18. Xu J, Lloyd DJ, Hale C, Stanislaus S, Chen M, Sivits G, et al. Fibroblast growth factor 21 reverses hepatic steatosis, increases energy expenditure, and improves insulin sensitivity in diet-induced obese mice. Diabetes. 2009;58:250-9. https://doi.org/10.2337/db08-0392.

19. So WY, Leung PS. Fibroblast growth factor 21 as an emerging therapeutic target for type 2 diabetes mellitus. Med Res Rev. 2016;36:672-704. https://doi.org/10.1002/med.21390.

20. Restelli LM, Oettinghaus B, Halliday M, Agca C, Licci M, Sironi L, et al. Neuronal mitochondrial dysfunction activates the integrated stress response to induce fibroblast growth factor 21. Cell Rep. 2018;24:1407-14. https://doi. org/10.1016/j.celrep.2018.07.023.

21. Taliyan R, Chandran SK, Kakoty V. Therapeutic approaches to Alzheimer's type of dementia: a focus on FGF21 mediated neuroprotection. Curr Pharm Des. 2019;25:2555-68. https://doi.org/10.2174/1381612825666190716101411.

22. Tanaka T, Biancotto A, Moaddel R, Moore AZ, GonzalezFreire M, Aon MA, et al. Plasma proteomic signature of age in healthy humans. Aging Cell. 2018;17:e12799. https://doi. org/10.1111/acel.12799.

23. Lehallier B, Gate D, Schaum N, Nanasi T, Lee SE, Yousef $\mathrm{H}$, et al. Undulating changes in human plasma proteome profiles across the lifespan. Nat Med. 2019;25:1843-50. https://doi.org/10.1038/s41591-019-0673-2. 
24. Conte M, Martucci M, Mosconi G, Chiariello A, Cappuccilli $\mathrm{M}$, Totti V, et al. GDF15 plasma level is inversely associated with level of physical activity and correlates with markers of inflammation and muscle weakness. Front Immunol. 2020;11:915. https://doi.org/10.3389/fimmu.2020.00915.

25. Luan $\mathrm{HH}$, Wang A, Hilliard BK, et al. GDF15 Is an Inflammation-Induced Central Mediator of Tissue Tolerance. Cell. 2019;178:1231-1244.e11.

26. Moon JS, Goeminne LJE, Kim JT, et al. Growth differentiation factor 15 protects against the aging-mediated systemic inflammatory response in humans and mice. Aging Cell. 2020:e13195. https://doi.org/10.1111/acel.13195.

27. Adela R, Banerjee SK. GDF-15 as a target and biomarker for diabetes and cardiovascular diseases: a translational prospective. J Diabetes Res. 2015;2015:490842-14. https://doi. org/10.1155/2015/490842. Review.

28. Natali A, Nesti L, Venturi E, Shore AC, Khan F, Gooding K, et al. Metformin is the key factor in elevated plasma growth differentiation factor-15 levels in type 2 diabetes: a nested, case-control study. Diabetes Obes Metab. 2019;21(2):4126. https://doi.org/10.1111/dom.13519.

29. Guo B, Zhai D, Cabezas E, Welsh K, Nouraini S, Satterthwait AC, et al. Humanin peptide suppresses apoptosis by interfering with Bax activation. Nature. 2003;423: 456-61.

30. Thummasorn S, Shinlapawittayatorn K, Khamseekaew J, Jaiwongkam T, Chattipakorn SC, Chattipakorn N. Humanin directly protects cardiac mitochondria against dysfunction initiated by oxidative stress by decreasing complex I activity. Mitochondrion. 2018;38:31-40. https://doi. org/10.1016/j.mito.2017.08.001.

31. Zhao ST, Zhao L, Li JH. Neuroprotective peptide humanin inhibits inflammatory response in astrocytes induced by lipopolysaccharide. Neurochem Res. 2013;38:581-8. https://doi.org/10.1007/s11064-012-0951-6.

32. Muzumdar RH, Huffman DM, Atzmon G, Buettner C, Cobb LJ, Fishman S, et al. Humanin: a novel central regulator of peripheral insulin action. PLoS One. 2009;4(7):e6334. https://doi.org/10.1371/journal.pone.0006334.

33. Lee C, Wan J, Miyazaki B, Fang Y, Guevara-Aguirre J, Yen $\mathrm{K}$, et al. IGF-I regulates the age-dependent signaling peptide humanin. Aging Cell. 2014;13(5):958-61. https://doi. org/10.1111/acel.12243.

34. Salemi M, Ridolfo F, Salluzzo MG, Cannarrella R, Giambirtone M, Caniglia S, et al. Humanin gene expression in fibroblast of Down syndrome subjects. Int J Med Sci. 2020;17(3):320-4. https://doi.org/10.7150/ijms.39145.

35. Terry DF, Wilcox MA, McCormick MA, et al. Lower allcause, cardiovascular, and cancer mortality in centenarians' offspring. J Am Geriatr Soc. 2004;52:2074-6.

36. Bucci L, Ostan R, Cevenini E, et al. Centenarians' offspring as a model of healthy aging: a reappraisal of the data on Italian subjects and a comprehensive overview. Aging (Albany NY). 2016;8:510-9. https://doi.org/10.18632 /aging.100912.

37. Testa R, Vanhooren V, Bonfigli AR, Boemi M, Olivieri F, Ceriello A, et al. N-glycomic changes in serum proteins in type 2 diabetes mellitus correlate with complications and with metabolic syndrome parameters. PLoS One. 2015;10(3):e0119983. https://doi.org/10.1371/journal. pone. 0119983 .
38. Sims R, van der Lee SJ, Naj AC, et al. Rare coding variants in PLCG2, ABI3, and TREM2 implicate microglialmediated innate immunity in Alzheimer's disease. Nat Genet. 2017;49(9):1373-84. https://doi.org/10.1038 /ng.3916.

39. Mensà E, Giuliani A, Matacchione G, Gurău F, Bonfigli AR, Romagnoli F, et al. Circulating miR-146a in healthy aging and type 2 diabetes: age- and gender-specific trajectories. Mech Ageing Dev. 2019;180:1-10. https://doi.org/10.1016 /j.mad.2019.03.001.

40. Levey AS, Stevens LA, Schmid CH, Zhang YL, Castro AF III, Feldman HI, et al. A new equation to estimate glomerular filtration rate. Ann Intern Med. 2009;150:604-12. https://doi.org/10.7326/0003-4819-150-9-20090505000006.

41. DeLong ER, DeLong DM, Clarke-Pearson DL. Comparing the areas under two or more correlated receiver operating characteristic curves: a nonparametric approach. Biometrics. 1988;44(3):837-45.

42. Chen WW, Li L, Yang GY, Li K, Qi XY, Zhu W, et al. Circulating FGF-21 levels in normal subjects and in newly diagnose patients with type 2 diabetes mellitus. Exp Clin Endocrinol Diabetes. 2008;116(1):65-8. https://doi. org/10.1055/s-2007-985148.

43. Chavez AO, Molina-Carrion M, Abdul-Ghani MA, Folli F, DeFronzo RA, Tripathy D. Circulating fibroblast growth factor-21 is elevated in impaired glucose tolerance and type 2 diabetes and correlates with muscle and hepatic insulin resistance. Diabetes Care. 2009;32(8):1542-6.

44. Wang YS, Ye J, Cao YH, Zhang R, Liu Y, Zhang SW, et al. Increased serum/plasma fibroblast growth factor 21 in type 2 diabetes mellitus: a systematic review and meta-analysis. Postgrad Med J. 2019;95(1121):134-9. https://doi. org/10.1136/postgradmedj-2018-136002.

45. Schnurr TM, Jakupović H, Carrasquilla GD, et al. Obesity, unfavourable lifestyle and genetic risk of type 2 diabetes: a case-cohort study [published online ahead of print, 2020 Apr 15]. Diabetologia. 2020. https://doi.org/10.1007 /s00125-020-05140-5.

46. Coll AP, Chen M, Taskar P, et al. GDF15 mediates the effects of metformin on body weight and energy balance [published correction appears in Nature. 2020;578(7795): 444-448. https://doi.org/10.1038/s41586-019-1911-y.

47. Calanna S, Scicali R, Di Pino A, et al. Lipid and liver abnormalities in haemoglobin A1c-defined prediabetes and type 2 diabetes. Nutr Metab Cardiovasc Dis. 2014;24:670 6. https://doi.org/10.1016/j.numecd.2014.01.013.

48. Scicali R, Di Pino A, Ferrara V, et al. New treatment options for lipid-lowering therapy in subjects with type 2 diabetes. Acta Diabetol. 2018;55:209-18. https://doi.org/10.1007 /s00592-017-1089-4.

49. Laws A, Reaven GM. Evidence for an independent relationship between insulin resistance and fasting plasma HDLcholesterol, triglyceride and insulin concentrations. J Intern Med. 1992;231:25-30. https://doi.org/10.1111/j.13652796.1992.tb00494.x.

50. Scicali R, Giral P, D'Erasmo L, Cluzel P, Redheuil A, di Pino A, et al. High TG to HDL ratio plays a significant role on atherosclerosis extension in prediabetes and newly diagnosed type 2 diabetes subjects. Diabetes Metab Res Rev. 2020;18:e3367. https://doi.org/10.1002/dmrr.3367. 
51. Carlsson AC, Nowak C, Lind L, Östgren CJ, Nyström FH, Sundström J, et al. Growth differentiation factor 15 (GDF$15)$ is a potential biomarker of both diabetic kidney disease and future cardiovascular events in cohorts of individuals with type 2 diabetes: a proteomics approach. Ups J Med Sci. 2020;125:37-43. https://doi.org/10.1080 /03009734.2019.1696430.

52. Laiteerapong N, Ham SA, Gao Y, Moffet HH, Liu JY, Huang ES, et al. The legacy effect in type 2 diabetes: impact of early glycemic control on future complications (the Diabetes \& Aging Study). Diabetes Care. 2019;42(3):41626. https://doi.org/10.2337/dc17-1144.

53. Lai YR, Huang CC, Chiu WC, Liu RT, Tsai NW, Wang HC, et al. HbA1C variability is strongly associated with the severity of cardiovascular autonomic neuropathy in patients with type 2 diabetes after longer diabetes duration. Front Neurosci. 2019;13:458. https://doi.org/10.3389 /fnins.2019.00458.

54. Simonovitch S, Schmukler E, Masliah E, Pinkas-Kramarski $\mathrm{R}$, Michaelson DM. The effects of APOE4 on mitochondrial dynamics and proteins in vivo. J Alzheimers Dis. 2019;70: 861-75. https://doi.org/10.3233/JAD-190074.

55. He K, Nie L, Zhou Q, Rahman SU, Liu J, Yang X, et al. Proteomic profiles of the early mitochondrial changes in APP/PS 1 and ApoE4 transgenic mice models of Alzheimer's disease. J Proteome Res. 2019;18:2632-42. https://doi.org/10.1021/acs.jproteome.9b00136.

56. Farmer BC, Kluemper J, Johnson LA. Apolipoprotein E4 alters astrocyte fatty acid metabolism and lipid droplet formation. Cells. 2019;8(2):182. https://doi.org/10.3390 /cells8020182.

57. Mottis A, Herzig S, Auwerx J. Mitocellular communication: shaping health and disease. Science. 2019;366(6467):82732. https://doi.org/10.1126/science.aax3768.

58. Gong Z, Tas E, Muzumdar R. Humanin and age-related diseases: a new link? Front Endocrinol (Lausanne). 2014;5:210. https://doi.org/10.3389/fendo.2014.00210.

59. Ji X, Zhao L, Ji K, Zhao Y, Li W, Zhang R, et al. Growth differentiation factor 15 is a novel diagnostic biomarker of mitochondrial diseases. Mol Neurobiol. 2017;54:8110-6. https://doi.org/10.1007/s12035-016-0283-7.

60. Scholle LM, Lehmann D, Deschauer M, Kraya T, Zierz S. FGF-21 as a potential biomarker for mitochondrial diseases. Curr Med Chem. 2018;25:2070-81. https://doi.org/10.2174 /0929867325666180111094336.

61. De Felice FG, Ferreira ST. Inflammation, defective insulin signaling, and mitochondrial dysfunction as common molecular denominators connecting type 2 diabetes to Alzheimer disease. Diabetes. 2014;63:2262-72. https://doi. org/10.2337/db13-1954.

62. Sun Y, Ma C, Sun H, et al. Metabolism: a novel shared link between diabetes mellitus and Alzheimer's disease. J Diabetes Res. 2020;2020:4981814. Published 2020 Jan 29. https://doi.org/10.1155/2020/4981814.

63. Wang KC, Woung LC, Tsai MT, Liu CC, Su YH, Li CY. Risk of Alzheimer's disease in relation to diabetes: a population-based cohort study. Neuroepidemiology. 2012;38:237-44. https://doi.org/10.1159/000337428.

64. Berezin AE. Diabetes mellitus related biomarker: the predictive role of growth-differentiation factor-15. Diabetes Metab
Syndr. 2016;10:S154-7. https://doi.org/10.1016/j. dsx.2015.09.016.

65. Kim HW, Lee JE, Cha JJ, Hyun YY, Kim JE, Lee MH, et al. Fibroblast growth factor 21 improves insulin resistance and ameliorates renal injury in $\mathrm{db} / \mathrm{db}$ mice. Endocrinology. 2013;154:3366-76. https://doi.org/10.1210/en.2012-2276.

66. Jimenez V, Jambrina C, Casana E, et al. FGF21 gene therapy as treatment for obesity and insulin resistance. EMBO Mol Med. 2018;10:e8791. https://doi.org/10.15252 /emmm.201708791.

67. Santoso P, Nakata M, Shiizaki K, Boyang Z, Parmila K, Otgon-Uul Z, et al. Fibroblast growth factor 21, assisted by elevated glucose, activates paraventricular nucleus NUCB2/ Nesfatin-1 neurons to produce satiety under fed states. Sci Rep. 2017;7:45819. https://doi.org/10.1038/srep45819.

68. Voigt A, Jelinek HF. Humanin: a mitochondrial signaling peptide as a biomarker for impaired fasting glucose-related oxidative stress. Phys Rep. 2016;4:e12796. https://doi. org/10.14814/phy2.12796.

69. Ramanjaneya M, Bettahi I, Jerobin J, et al. Mitochondrialderived peptides are down regulated in diabetes subjects. Front Endocrinol (Lausanne). 2019;10:331. https://doi. org/10.3389/fendo.2019.00331.

70. Chai YL, Hilal S, Chong JP, et al. Growth differentiation factor-15 and white matter hyperintensities in cognitive impairment and dementia. Medicine (Baltimore). 2016;95: e4566. https://doi.org/10.1097/MD.0000000000004566.

71. Maetzler W, Deleersnijder W, Hanssens V, Bernard A, Brockmann K, Marquetand J, et al. GDF15/MIC1 and MMP9 cerebrospinal fluid levels in Parkinson's disease and Lewy body dementia. PLoS One. 2016;11:e0149349. https://doi.org/10.1371/journal.pone.0149349.

72. Yao X, Wang D, Zhang L, Wang L, Zhao Z, Chen S, et al. Serum growth differentiation factor 15 in Parkinson disease. Neurodegener Dis. 2017;17:251-60. https://doi.org/10.1159 /000477349.

73. Chen S, Chen ST, Sun Y, Xu Z, Wang Y, Yao SY, et al. Fibroblast growth factor 21 ameliorates neurodegeneration in rat and cellular models of Alzheimer's disease. Redox Biol. 2019;22:101133. https://doi.org/10.1016/j. redox.2019.101133.

74. Osorio RS, Pirraglia E, Agüera-Ortiz LF, During EH, Sacks H, Ayappa I, et al. Greater risk of Alzheimer's disease in older adults with insomnia. J Am Geriatr Soc. 2011;59:55962. https://doi.org/10.1111/j.1532-5415.2010.03288.x.

75. Martucci M, Conte M, Ostan R, et al. Both objective and paradoxical insomnia elicit a stress response involving mitokine production. Aging (Albany NY). 2020;12:10497505. https://doi.org/10.18632/aging.103274.

76. Hashimoto Y, Niikura T, Ito Y, Sudo H, Hata M, Arakawa $\mathrm{E}$, et al. Detailed characterization of neuroprotection by a rescue factor humanin against various Alzheimer's diseaserelevant insults. J Neurosci. 2001;21:9235-45. https://doi. org/10.1523/JNEUROSCI.21-23-09235.2001.

77. Chai GS, Duan DX, Ma RH, Shen JY, Li HL, Ma ZW, et al. Humanin attenuates Alzheimer-like cognitive deficits and pathological changes induced by amyloid $\beta$-peptide in rats. Neurosci Bull. 2014;30:923-35. https://doi.org/10.1007 /s12264-014-1479-3.

78. Yen K, Wan J, Mehta HH, et al. Humanin prevents agerelated cognitive decline in mice and is associated with 
improved cognitive age in humans. Sci Rep. 2018;8:14212. Published 2018 Sep 21. https://doi.org/10.1038/s41598018-32616-7.

79. Yen K, Mehta HH, Kim SJ, et al. The mitochondrial derived peptide humanin is a regulator of lifespan and healthspan. Aging (Albany NY). 2020;12:11185-99. https://doi. org/10.18632/aging.103534.

80. Bachar AR, Scheffer L, Schroeder AS, Nakamura HK, Cobb $\mathrm{LJ}, \mathrm{Oh} \mathrm{YK}$, et al. Humanin is expressed in human vascular walls and has a cytoprotective effect against oxidized LDLinduced oxidative stress. Cardiovasc Res. 2010;88:360-6. https://doi.org/10.1093/cvr/cvq191.
81. Widmer RJ, Flammer AJ, Herrmann J, Rodriguez-Porcel M, Wan J, Cohen P, et al. Circulating humanin levels are associated with preserved coronary endothelial function. Am J Physiol Heart Circ Physiol. 2013;304:H393-7. https://doi.org/10.1152/ajpheart.00765.2012.

Publisher's note Springer Nature remains neutral with regard to jurisdictional claims in published maps and institutional affiliations. 